\title{
Direct Production of Iso-Paraffins from Syngas over Hierarchical Cobalt-ZSM-5 Nanocomposites Synthetized using Carbon Nanotubes as Sacrificial Templates
}

\author{
Camila Flores $^{[a], ~[b]}$, Nuno Batalha ${ }^{[a]}$, Vitaly V. Ordomsky ${ }^{[a]}$, Vladimir L. Zholobenko ${ }^{[c]}$, Walid Baaziz ${ }^{d}$, \\ Nilson R. Marcilio ${ }^{[b]}$ and Andrei Y. Khodakov *[a]
}

\begin{abstract}
This paper focuses on the effect of synthesis conditions on the structure of cobalt-ZSM-5 zeolites, localization, dispersion and reducibility of cobalt species and their catalytic performance in Fischer-Tropsch synthesis. The zeolite catalysts were prepared using carbon nanotubes as sacrificial templates. Addition of pristine carbon nanotubes resulted only in a slight increase in the zeolite mesoporosity, while the presence of carbon nanotubes impregnated with cobalt drastically modified the zeolite morphology and texture. The zeolite mesoporous volume increased by 3-4 times. The catalysts prepared using cobalt impregnated carbon nanotubes as templates showed 5-8 times higher Fischer-Tropsch reaction rates normalized by reducible cobalt compared to the catalysts prepared by conventional impregnation. Higher selectivity to isomerized branched hydrocarbons on these zeolites was attributed to the enhanced diffusion favoring removal of isomerized products and avoiding their cracking.
\end{abstract}

\section{Introduction}

The depletion of fossil resources and increasing environmental concerns have led to the necessity for the development of new catalytic processes from alternative renewable resources. Natural gas and biomass can be transformed into syngas $\left(\mathrm{H}_{2} / \mathrm{CO}\right)$ and subsequently by Fischer-Tropsch (FT) synthesis over cobalt-based catalysts into middle distillates and waxes [13]. FT synthesis is a "nontrivial surface polymerization reaction" [4], with reaction selectivity typically described by the broad and

[a] Ms. C. Flores, Dr N. Batalha, Dr V. V. Ordomsky, Dr A. Y. Khodakov*

Univ. Lille, CNRS, Centrale Lille, ENSCL, Univ. Artois, UMR 8181 UCCS - Unité de Catalyse et Chimie du Solide, F-59000 Lille,

France

E-mail: andrei.khodakov@univ-lille1.fr

[b] Ms. C. Flores, Prof. N.R. Marcilio

Department of Chemical Engineering, Federal University of Rio Grande do Sul - UFRGS, Rua Luiz Englert, s/nº, 90040-040, Porto Alegre/RS, Brazil

[c] Dr V. L. Zholobenko

Lennard-Jones Laboratories, Keele University, Staffordshire ST5 5BG, UK

[d] Dr. W. Baaziz

IPCMS, Université de Strasbourg, 23, rue du Loess BP 43, F-67034 Strasbourg, France

Supporting information for this article is given via a link at the end of the document

unselective Anderson-Schulz-Flory
Consequently, the major challenge of FT reaction is to tune the reaction selectivity to specific hydrocarbon fractions.

Several methods have been proposed for selectivity control in FT synthesis. First, catalytic cracking/isomerization of FT hydrocarbons can upgrade the reaction products to a specific fuel. Combination of FT synthesis with hydrocracking and isomerization of long chain hydrocarbons restricts the hydrocarbon distribution to a more convenient range [6]. The isomerization and cracking of $\mathrm{FT}$ hydrocarbons would lead to iso-paraffins or diesel fuels constituted by the $C_{10}-C_{20}$ hydrocarbons. This multistage process, however, significantly reduces the efficiency of synthetic fuel production.

An alternative to that multi-stage process would be to utilize bifunctional catalysts containing an active FT component, e.g. Co or Ru, and an acid catalyst active for cracking and isomerization. The proximity between metal and acid sites is an important parameter of the bifunctional catalysts often governing reaction rate and selectivities. Recently two additional methods for hydrocarbon selectivity control were proposed, which involve making use of nanoreactors [7] and microemulsions [8]. In these methods the carbon chain length is limited by steric and diffusion limitations.

Zeolites have been often suggested as promising catalysts for hydrocarbon cracking and isomerization under the conditions similar to FT synthesis [3, 9]. An FT catalyst can be combined with a zeolite through several different methods: in a dual bed catalytic reactor with FT catalyst in the first layer followed by zeolite [10, 11]; in hybrid catalysts prepared by mixing of FT catalyst and zeolite [12-14]; in the catalysts prepared by zeolite impregnation with metal salts [13, 15-18]; and by composite zeolite/metal catalysts, e.g. core-shell [19, 20].

A significant number of research publications have been dedicated to direct synthesis of gasoline and middle distillates over dual bed or hybrid catalysts obtained through combination of supported Co catalysts and zeolites [10-16, 21-23]. Different types of zeolite frameworks such as ZSM-5, MCM-22, IM-5, ITQ2, BEA, MOR, and FAU with and without addition of noble-metal promoters have been tested and combined with FT synthesis catalysts. Still, slow diffusion of long-chain paraffins through zeolite pores, in particular on medium-pore zeolites, leads to a preferential participation of the acid sites on the zeolite external surface and lower isomerization efficiency [22].

Impregnation is another method for the preparation of bifunctional Co-zeolite catalysts for direct production of fuels from syngas [13, 15-18, 24-26]. Still, this method presents a major drawback, that is the neutralization of the zeolite acid sites by cobalt ions. Cobalt ions, introduced during impregnation, can 
occupy cation positions in the zeolite framework decreasing the number of acid sites available for hydrocarbon isomerization and cracking, while larger cobalt oxide particles can be detected on the outer surface of zeolite. Additionally, isolated Co cations in the zeolite framework are very difficult to reduce to metallic cobalt. Cobalt species on the zeolite outer surface have low dispersion and generate insufficient number of active sites for FT reaction. This decreases the amount of active phase for FT synthesis.

The improvement of zeolite diffusion properties through creating a hierarchical porous network has been the subject of extensive research [27-30]. The application of this type of materials was proven to be beneficial for the activity and selectivity of several catalytic reactions including long-chain paraffin isomerization and cracking combined with FT synthesis [26, 29-33]. Several synthesis methodologies, classified as top-down and bottom-up, have be applied to the synthesis of hierarchical zeolites. A mesoporous network can be created directly by partially destroying the zeolite crystal through desilication [27, 34] or dealumination $[35,36]$. Alternatively, hierarchical zeolites can be produced directly during the zeolite synthesis through the use of external templates that are sacrificed after zeolite synthesis, e.g. carbon structures [28, 37] resins [38] or polymers [39]. It is important to emphasize that cobalt is usually added to the zeolites in the second step after hierarchization of the zeolite.

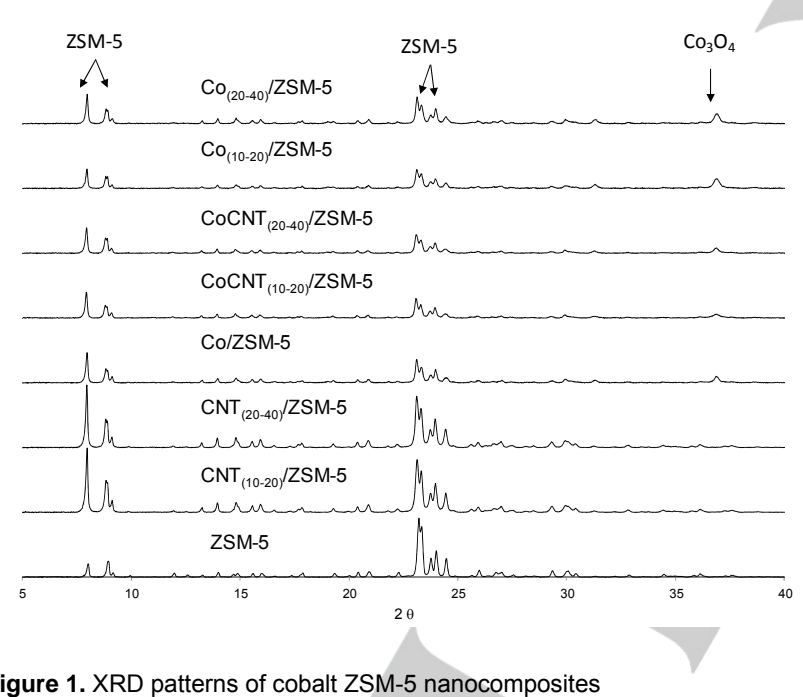

Figure 1. XRD patterns of cobalt ZSM-5 nanocomposites

The goal of this work is to obtain in a one-pot synthesis composite hierarchical zeolites with cobalt metal particles uniformly distributed in the zeolite mesoporous structure. This has been achieved by using cobalt impregnated carbon nanotubes (Co/CNT) as sacrificial templates during the synthesis of ZSM- 5 zeolite. Two different carbon nanotubes (CNT) with outer diameters of $10-20 \mathrm{~nm}$ and $20-40 \mathrm{~nm}$ were used to induce mesoporosity in ZSM-5. The catalysts were characterized by low-temperature $\mathrm{N}_{2}$ adsorption, Transmission electron microscopy (TEM), Temperature-Programmed
Reduction (TPR) and FTIR spectroscopy with adsorbed pyridine (Py). The hierarchical cobalt-zeolite samples were tested in FT synthesis and their catalytic performance in particular relative to synthesis of iso-paraffins was compared with the Co/ZSM-5 catalysts prepared by conventional impregnation.

The synthesized samples were denoted as: $\operatorname{CoCNT}_{(\mathrm{x})} / \mathrm{ZSM}-5$ for the samples synthesized with cobalt and platinum coimpregnated CNT ( $x$ represents the CNT diameter used in the synthesis, i.e. $10-20$ or $20-40 \mathrm{~nm}$ ); $\mathrm{Co}_{(\mathrm{x})} / \mathrm{ZSM}-5$ for the samples synthesized with CNT and subsequently impregnated with Co and $\mathrm{Pt}$ ( $\mathrm{x}$ represents the CNT diameter used in the synthesis, i.e. $10-20 \mathrm{~nm}$ or $20-40 \mathrm{~nm})$. Co/ZSM-5 stands for the zeolite synthetized without addition of CNT and impregnated with the $\mathrm{Co}$ and $\mathrm{Pt}$ precursors. Further details are available in Experimental Section.

\section{Results and Discussion}

\section{Catalyst structure}

The XRD patterns of the synthesized samples are displayed in Figure 1. All samples present characteristic peaks of MFI zeolite. The presence of CNT during hydrothermal treatment does not affect to any noticeable degree the intensity of the XRD peaks. The introduction of cobalt by impregnation or with CNT during the zeolite synthesis led to an overall reduction of the intensity of the zeolite characteristic peaks. This was attributed to the effect of "dilution" and lower concentration of MFI phase in these samples. The $\mathrm{Co}_{3} \mathrm{O}_{4}$ phase was detected using a characteristic peak at $2 \theta$ equal to $36.8^{\circ}$ in all samples containing cobalt. The particle size of $\mathrm{Co}_{3} \mathrm{O}_{4}$ calculated using the Scherrer equation (Table 1) was in all cases between 27 and $44 \mathrm{~nm}$, indicating that a large fraction of cobalt is located either in the mesopores or on the zeolite external surface. Interestingly, smaller diameter CNT (10-20 nm) during zeolite crystallization led to the formation of smaller $\mathrm{Co}_{3} \mathrm{O}_{4}$ particles, i.e. around $30 \mathrm{~nm}$, when compared with the synthesis without CNT or using larger diameter CNT (20-40 $\mathrm{nm})$.

Table 1. Catalyst textural characterization

\begin{tabular}{|c|c|c|c|c|c|c|}
\hline \multirow[b]{2}{*}{ Sample } & \multicolumn{4}{|c|}{$\mathrm{N}_{2}$ adsorption } & \multirow[b]{2}{*}{$\begin{array}{c}\text { Co } \\
\text { content } \\
\text { (wt \%) }\end{array}$} & \multirow{2}{*}{$\begin{array}{c}\mathrm{Co}_{3} \mathrm{O}_{4} \\
\text { Particle } \\
\text { size } \\
(\mathrm{nm})\end{array}$} \\
\hline & $\begin{array}{c}\mathrm{S}_{\mathrm{BET}} \\
\left(\mathrm{m}^{2} \mathrm{~g}^{-1}\right)\end{array}$ & $\begin{array}{c}V_{\text {tot }} \\
\left(\mathrm{cm}^{3} \mathrm{~g}^{-}\right. \\
1)\end{array}$ & $\begin{array}{c}V_{\text {mic }} \\
\left(\mathrm{cm}^{3} \mathrm{~g}^{-}\right.\end{array}$ & $\begin{array}{l}V_{\text {meso }} \\
\left(m^{2} g^{-}\right. \\
1)\end{array}$ & & \\
\hline ZSM-5 & 425 & 0.19 & 0.13 & 0.06 & - & - \\
\hline $\mathrm{CNT}_{(10-20)} / \mathrm{ZSM}-5$ & 434 & 0.21 & 0.12 & 0.09 & - & - \\
\hline $\mathrm{CNT}_{(20-40)} / \mathrm{ZSM}-5$ & 418 & 0.21 & 0.10 & 0.11 & - & - \\
\hline Co/ZSM-5 & 372 & 0.17 & 0.11 & 0.06 & 15.6 & 44 \\
\hline $\mathrm{Co}_{(10-20)} / Z S M-5$ & 360 & 0.18 & 0.10 & 0.08 & 13.2 & 27 \\
\hline $\mathrm{Co}_{(20-40)} / Z S M-5$ & 276 & 0.13 & 0.08 & 0.05 & 12.7 & 40 \\
\hline $\mathrm{CoCNT}_{(10-20)} / \mathrm{ZSM}-5$ & 435 & 0.32 & 0.09 & 0.23 & 7.8 & 29 \\
\hline $\operatorname{CoCNT}_{(20-40)} / Z S M-5$ & 395 & 0.25 & 0.09 & 0.16 & 9.4 & 42 \\
\hline
\end{tabular}




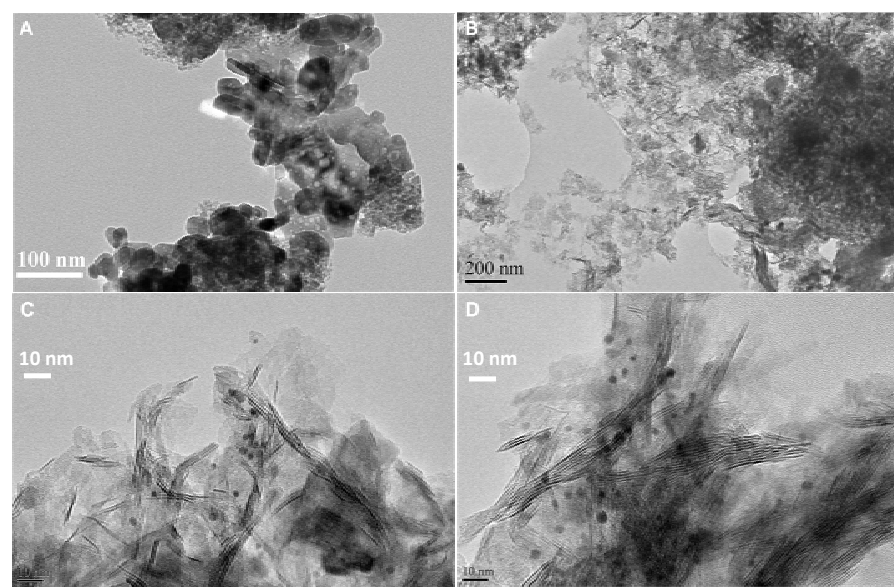

Figure 2. TEM images of $\mathrm{Co}_{(10-20)} / \mathrm{ZSM}-5$ (A), $\operatorname{CoCNT}_{(10-20)} / \mathrm{ZSM}-5(\mathrm{~B})$, $\mathrm{CoCNT}_{(10-20)} / \mathrm{ZSM}-5$ high magnification(C) and $\mathrm{CoCNT}_{(20-40)} / \mathrm{ZSM}-5$ high magnification

The catalyst textural properties are listed in Table 1. The nitrogen adsorption desorption isotherms are displayed in Figure S1 (Supporting information, SI). The introduction of CNT without cobalt in the zeolite synthesis gel did not affect to any greater extent the zeolite overall surface area. However, the catalyst porosity undergoes significant changes. The mesoporous volume of the zeolites prepared using the $10-20 \mathrm{~nm}$ and $20-40$ $\mathrm{nm}$ diameter CNT increased by $50 \%$ and $80 \%$, respectively. This variation is possibly caused by creating mesoporosity via removal of the CNT incorporated inside the zeolite crystals during crystallization [28].

After cobalt impregnation, a significant decrease in the sample surface area and pore volume was observed. This decrease was attributed to the presence of $\mathrm{Co}_{3} \mathrm{O}_{4}$ which can result in a partial plugging of the zeolite pores and "dilution" effect. In all cases, the impregnation with cobalt nitrate also caused a decrease in the zeolite microporous volume. This suggests that at least a part of cobalt is located inside the zeolite framework. The mesoporous volume was however slightly higher in the samples synthetized in the presence of CNT (without cobalt). This seems to confirm partial incorporation of CNT into zeolites during their synthesis and subsequent generation of mesoporosity during the CNT combustion.

The samples synthesized with Co/CNT as templates displayed surface area and microporous volume similar to the pure zeolite (Table 1), while the mesoporous volume was significantly increased. In comparison to the ZSM-5 samples synthesized with pristine CNT, the $\mathrm{COCNT}_{(10-20)} / \mathrm{ZSM}-5$ and $\mathrm{CoCNT}_{(20-}$ 40)/ZSM-5 mesoporous volume was, respectively, $185 \%$ and $220 \%$ higher than that of $\mathrm{Co}_{(10-20)} / \mathrm{ZSM}-5$ and $\mathrm{Co}_{(20-40)} / \mathrm{ZSM}-5$.

The impact of the CNT on the zeolite morphology was investigated by TEM (Figure 2). The zeolite crystallization in the presence of CNT led to the formation of large pores in the zeolite crystals (Figure 2A). These pores were formed after calcination when the CNT were removed from the zeolite. The zeolite phase clearly display imprinting coming from CNT which were partially encapsulated inside the zeolite crystals during germination [26]. The presence of these regularly shaped pores was not observed on zeolites crystallized in the presence of cobalt impregnated CNT (Figure $2 \mathrm{~B}$ ). In the presence of Co/CNT, the formed zeolite crystals took a less regular shape, in agreement with the higher mesopore volumes observed for calcined $\mathrm{CoCNT}_{(10-20)} / \mathrm{ZSM}-5$ and $\mathrm{CoCNT}_{(20-40)} / \mathrm{ZSM}-5$ (Table 1). Schematically the zeolite synthesis process in the presence of $\mathrm{Co} / \mathrm{CNT}$ is shown in Figure 3 . Figure $2 \mathrm{C}$ and Figure $2 \mathrm{D}$ show the formation of a uniform layered material. Importantly, these layered structures are only observed when cobalt was present in CNT added to the zeolite synthesis mixture. Indeed, the zeolite morphology replicates that of carbon nanotubes containing cobalt nanoparticles.

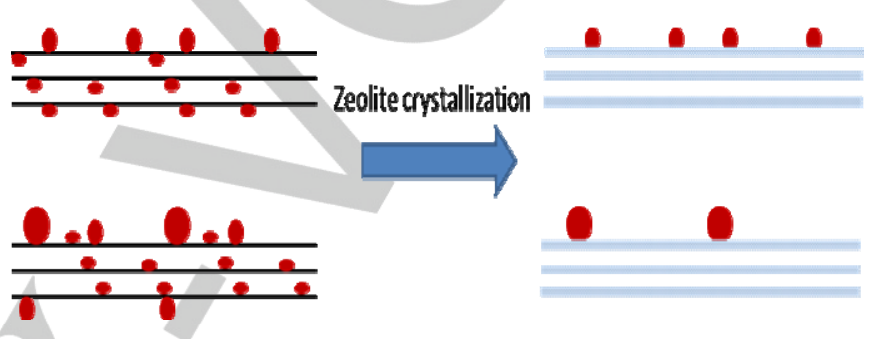

Figure 3. Synthesis of ZSM-5 zeolite using Co/CNT as sacrificial templates. Resulting zeolites replicate carbon nanotube morphology.

In addition, Figure 2C and Figure 2D display a large number of small $\mathrm{Co}_{3} \mathrm{O}_{4}$ particles with a diameter comprised between 1 and $5 \mathrm{~nm}$ as well as larger particles, i.e. $30-50 \mathrm{~nm}$. This suggests that the zeolite contains two types of cobalt particles: smaller cobalt particles of 1-5 $\mathrm{nm}$ are located in the zeolite meso- and micropores, while larger cobalt particles of $30-50 \mathrm{~nm}$ are situated in the zeolite mesopores and on the outer surface. Note that only large $\mathrm{Co}_{3} \mathrm{O}_{4}$ crystallites can be detected in the zeolites by XRD, while it is impossible to detect by XRD cobalt oxide particles smaller than $5 \mathrm{~nm}$.

To confirm uniform distribution of cobalt nanoparticles in the zeolite mesopores, we conducted additional experiments using the STEM-HAADF electron tomography. The typical slices (xy) and $(x z)$ extracted from the $3 D$ volume calculated by tomography of the sample CoCNT ${ }_{(20-40)} / Z S M-5$ prepared using $\mathrm{Co} \mathrm{CNT}_{(20-40)}$ as sacrificial template (Figure 4 ) show clearly the presence of cobalt nanoparticles inside the mesoporous structure of zeolite.

Thus, the electron microscopy results are clearly indicative of the important role of cobalt located on CNT for directing zeolite synthesis. Cobalt species probably act as zeolite nucleation sites for designing mesoporous zeolites with the CNT-type morphology (Figure 3).

The TPR profiles of the catalysts are shown in Figure 5 . The reduction profiles of the impregnated samples were consistent with the two-step $\mathrm{Co}_{3} \mathrm{O}_{4}$ reduction to metallic $\mathrm{Co}$. $\mathrm{Co}_{3} \mathrm{O}_{4}$ is first reduced to $\mathrm{CoO}$ which is then reduced to metallic $\mathrm{Co}$, thus leading to the formation of two $\mathrm{H}_{2}$ consumption peaks [13, 40]. In the samples prepared by impregnation, i.e. Co/ZSM-5, $\mathrm{Co}_{(10-}$ 20)/ZSM-5 and $\mathrm{Co}_{(20-40)} / \mathrm{ZSM}-5$, the characteristic $\mathrm{Co}_{3} \mathrm{O}_{4}$ reduction 

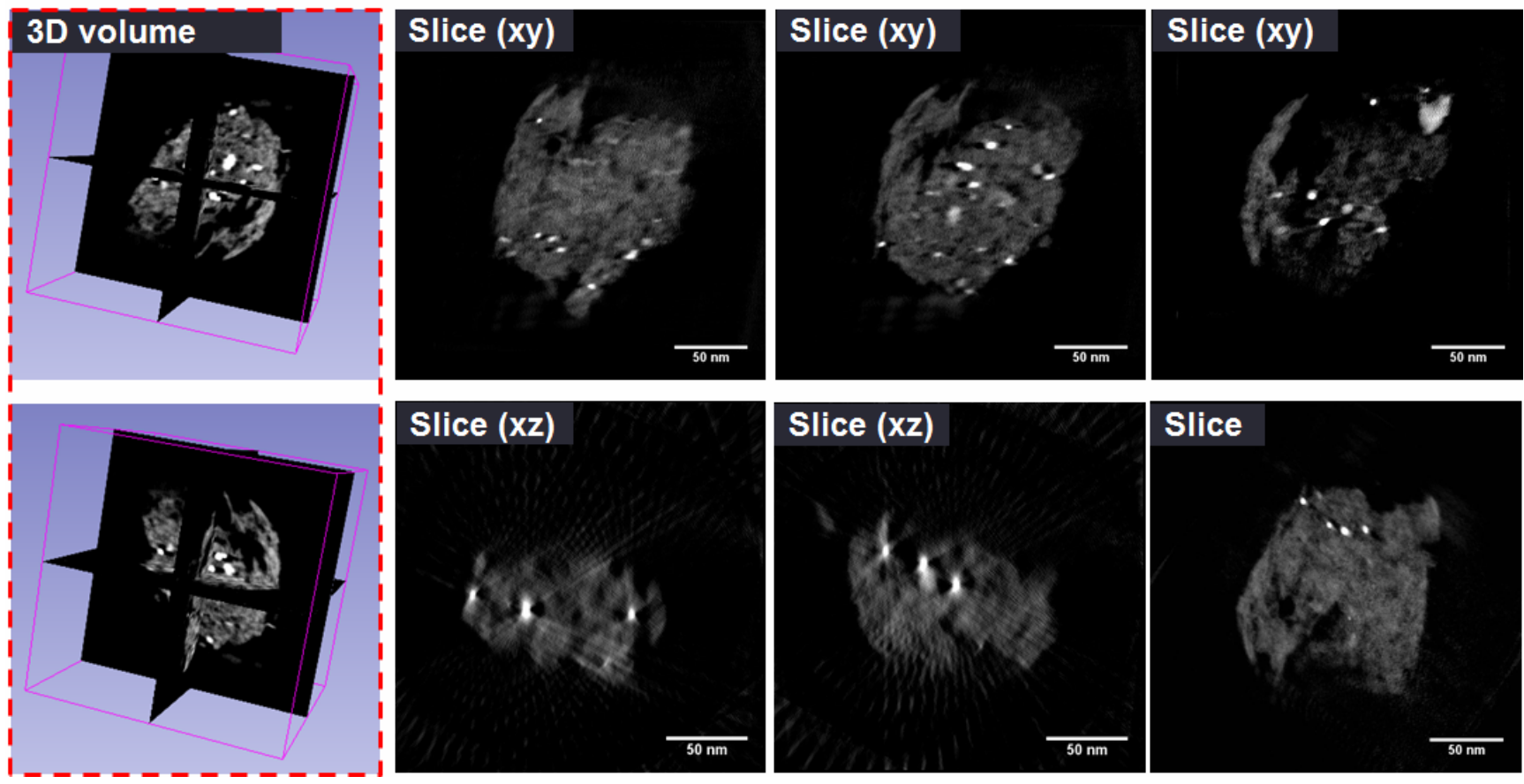

Figure 4. Results of STEM-HAADF electron tomography analysis of $\operatorname{CoCNT}_{(20-40)} \mathrm{ZSM}-5$ catalyst (3D volume and typical slices showing clearly the presence of cobalt nanoparticles inside the zeolite structure)

shoulder corresponding to the reduction of $\mathrm{Co}_{3} \mathrm{O}_{4}$ to $\mathrm{CoO}$.

No peaks at the temperatures higher than $400^{\circ} \mathrm{C}$ were observed indicating the absence of isolated exchanged cobalt ions or barely reducible cobalt silicates. Interestingly, the hydrogen consumption profiles were different in the samples synthesized through the germination of zeolite in the presence of Co impregnated CNT. The broad TPR peak which occurred at temperatures below $400{ }^{\circ} \mathrm{C}$, can be attributed to the reduction of $\mathrm{Co}_{3} \mathrm{O}_{4}$ crystallites to $\mathrm{CoO}$ and then to metallic $\mathrm{Co}[41,42]$. The second hydrogen consumption peak, observed at 700 $730^{\circ} \mathrm{C}$, suggests the presence of a more refractory cobalt phase.

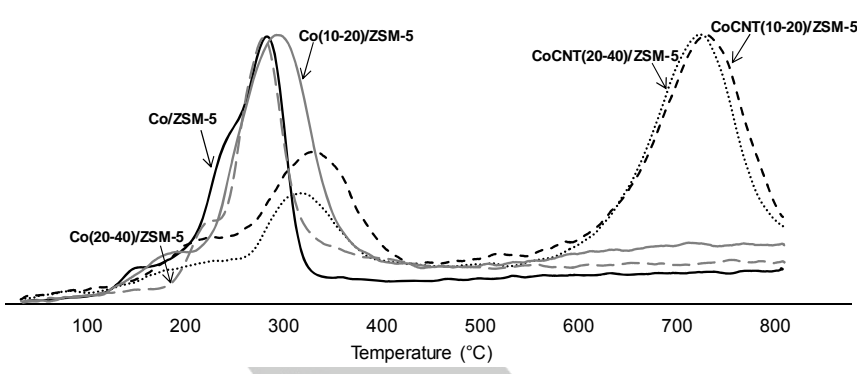

Figure 5. Temperature programmed reduction (TPR) profiles of the catalysts

The formation of amorphous cobalt silicates or aluminates is a possible explanation. Additionally, incorporation of cobalt in the discarded. Indeed, several authors have reported incorporation of transition metals, including cobalt, into zeolite framework when this metal was present during hydrothermal synthesis [4346]. The cobalt reducibility and acidity data evaluated from pyridine adsorption and FTIR spectroscopy data are given in Table 2.

Table 2. Catalyst acidity and cobalt reducibility

\begin{tabular}{|c|c|c|c|c|c|c|}
\hline \multirow[t]{2}{*}{ Sample } & \multirow{2}{*}{$\begin{array}{r}\mathrm{SiO}_{2} / \\
\mathrm{Al}_{2} \mathrm{O}_{3}{ }^{a}\end{array}$} & \multirow{2}{*}{$\begin{array}{l}\text { Extent of } \\
\text { cobalt } \\
\text { reduction } \\
(\%)\end{array}$} & \multicolumn{2}{|c|}{ Total acidity $^{c}$} & \multicolumn{2}{|c|}{$\begin{array}{l}\text { Fraction ofStrong } \\
\text { Acidity }^{\mathrm{d}}\end{array}$} \\
\hline & & & $\begin{array}{l}\text { Brønsted } \\
\left(\mu \text { molg }^{-1}\right)\end{array}$ & $\begin{array}{l}\text { Lewis } \\
\left(\mu \operatorname{molg}_{1}\right.\end{array}$ & Brønsted & Lewis \\
\hline Co/ZSM-5 & 24 & 82 & 160 & 530 & 0.688 & 0.708 \\
\hline $\mathrm{Co}_{(10-20)} / \mathrm{ZSM}-5$ & 25 & 69 & 150 & 520 & 0.733 & 0.769 \\
\hline $\mathrm{Co}_{(20-40)} / \mathrm{ZSM}-5$ & 22 & 58 & 195 & 560 & 0.769 & 0.768 \\
\hline $\begin{array}{l}\text { CoCNT }_{(10-20) /} \\
\text { ZSM-5 }\end{array}$ & 20 & 18 & 250 & 180 & 0.800 & 0.667 \\
\hline $\begin{array}{l}\text { CoCNT }_{(20-40)} \\
\text { /ZSM-5 }\end{array}$ & 21 & 7 & 295 & 130 & 0.847 & 0.846 \\
\hline
\end{tabular}

abulk. Determined by XRF

${ }^{b}$ calculated from low temperature $\left(<400^{\circ} \mathrm{C}\right)$ TPR peaks assuming reduction of $\mathrm{CO}_{3} \mathrm{O}_{4}$ into metallic cobalt

${ }^{\circ}$ determined by pyridine adsorption at $150^{\circ} \mathrm{C}$

${ }^{d}$ determined by pyridine adsorption at $350^{\circ} \mathrm{C}$ 
Table 3. Activity and selectivity of the catalysts for the Fischer-Tropsch synthesis reaction ( $\left.P=2 \mathrm{MPa}, \mathrm{GHSV}=20-70 \mathrm{~L} / \mathrm{h} \mathrm{g} \mathrm{Co}, \mathrm{T}=250{ }^{\circ} \mathrm{C}, \mathrm{H}_{2} / \mathrm{CO}=2\right)$

\begin{tabular}{|c|c|c|c|c|c|c|c|c|}
\hline \multirow[t]{2}{*}{ Catalyst } & \multirow{2}{*}{$\begin{array}{l}\text { FT reaction rate } \\
\left(\mathrm{mmol}_{\mathrm{co}} / \mathrm{h} . \mathrm{g}_{\mathrm{co}}\right)^{*}\end{array}$} & \multirow{2}{*}{$\begin{array}{c}\text { Conversion } \\
(\%)\end{array}$} & \multicolumn{6}{|c|}{ Selectivity (mol. C\%) } \\
\hline & & & $\mathrm{CH}_{4}$ & $\mathrm{C}_{2}-\mathrm{C}_{4}$ & $\begin{array}{c}\mathrm{C}_{2}-\mathrm{C}_{4} \\
\text { (olefin) }\end{array}$ & $\begin{array}{c}\mathrm{C}_{2}-\mathrm{C}_{4} \\
\text { (paraffin) }\end{array}$ & $\begin{array}{l}\mathrm{C}_{2}-\mathrm{C}_{4} \\
(\mathrm{P} / \mathrm{O})\end{array}$ & $\mathrm{C}_{5}^{+}$ \\
\hline Co/ZSM-5 & 244 & 39 & 32.8 & 19.0 & 2.7 & 16.3 & 6.0 & 48.1 \\
\hline $\mathrm{Co}_{(10-20)} / \mathrm{ZSM}-5$ & 371 & 28 & 28.9 & 18.4 & 2.0 & 16.4 & 8.2 & 52.7 \\
\hline $\mathrm{Co}_{(20-40)} / \mathrm{ZSM}-5$ & 204 & 29 & 37.1 & 29.8 & 1.5 & 28.3 & 18.9 & 33.1 \\
\hline $\mathrm{CoCNT}_{(10-20)} / \mathrm{ZSM}-5$ & $352(1961)^{\#}$ & 42 & 15.9 & 13.8 & 2.8 & 11.0 & 3.9 & 73.1 \\
\hline $\operatorname{CoCNT}_{(20-40)} / Z S M-5$ & $131(1893)^{\#}$ & 28 & 12.6 & 13.2 & 3.0 & 10.2 & 3.4 & 74.2 \\
\hline
\end{tabular}

*time at $24 \mathrm{~h}$.

\# In brackets: activity on the reducible cobalt basis.

The introduction of CNT or Co/CNT during the hydrothermal synthesis of the zeolite caused no significant variations on the $\mathrm{SiO}_{2} / \mathrm{Al}_{2} \mathrm{O}_{3}$ ratio. Significant changes in acid properties were observed between the impregnated samples and the ones when the Co was present during hydrothermal treatment. All the samples synthesized using cobalt nitrate impregnation of the zeolite displayed higher concentration of Lewis acid sites. Unsaturated sites in cobalt oxide particles are known to be responsible for the creation of Lewis acidity [47]. Therefore, higher concentration of Lewis acid sites in the impregnated samples could be related to the higher loading of cobalt oxide in these catalysts as shown by TPR (Figure 5). Much lower concentration of $\mathrm{Co}_{3} \mathrm{O}_{4}(18 \%$ and $7 \%$ respectively) was detected by TPR in $\mathrm{CoCNT}_{(10-2)} / \mathrm{ZSM}-5$ and $\mathrm{CoCNT}_{(20-40)} / \mathrm{ZSM}-5$. These samples showed lower concentration of Lewis acid sites. Note also that the samples synthesized through impregnation showed lower concentration of Brønsted acid sites in comparison with the catalysts synthesized in the presence of Co/CNT. The synthesis of the zeolite directly in the presence of $\mathrm{Co} / \mathrm{CNT}$ enables higher total Brønsted acid site concentration. Variation of IR intensity of bands attributed to Py adsorption on Brønsted and Lewis acid sites is shown in Figure S2 (SI). The zeolites synthetized using Co/CNT show a higher effective strength of Brønsted acid sites, compared to the samples prepared by impregnation, while the impregnated samples have a much higher concentration of stronger Lewis acid sites (Table 2).

\section{Catalytic performance in FT synthesis}

The results of the FT catalytic evaluation of the materials are shown in Table 3, Figure 6 and S3, SI. FT reaction rate varies between 131 and $371 \mathrm{mmol}$ co/h.gco. The catalytic performance of cobalt zeolite catalysts was tested for at least 30 h. No noticeable evolution of catalytic performance was observed under these conditions. The samples were organized with respect to their activity in the following order: $\mathrm{Co}_{(10-20)} / Z S M-5>$ $\mathrm{CoCNT}_{(10-20)} / \mathrm{ZSM}-5>\mathrm{Co}_{(20-40)} / Z \mathrm{ZSM}-5>\mathrm{Co} / \mathrm{ZSM}-5>\mathrm{CoCNT}_{(20-}$ $\left.{ }_{40}\right) / Z S M-5$. The catalytic performance of cobalt catalysts depends on the density of cobalt metallic active sites. Cobalt reducibility is therefore an important parameter.

While, the TPR profiles of the samples prepared by impregnation suggest the presence of cobalt species reducible at temperatures lower than $450^{\circ} \mathrm{C}$, the TPR profiles (Figure 5) of the $\operatorname{CoCNT}_{(10-20)} / Z \mathrm{ZSM}-5$ and $\operatorname{CoCNT}_{(20-40)} / \mathrm{ZSM}-5$ samples synthetized using Co/CNT templates show that only a small portion of the cobalt is reducible at $400^{\circ} \mathrm{C}$. Consequently, the
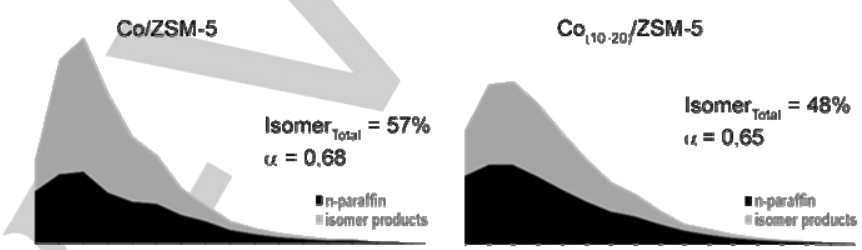

9 1011121314151817 18 $19202122232425 \quad 81011121314151617$ 18 $18202122 \quad 32425$
$\mathrm{Co}_{(20.40)}$ IZSM-5

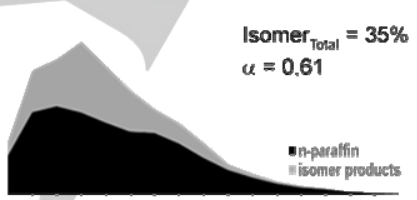

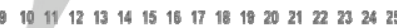

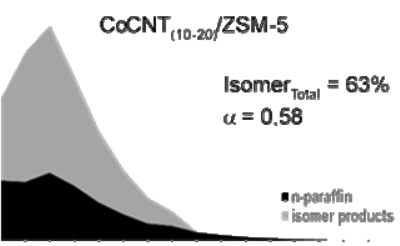

8 $10111213141516171818202122 \quad 232425$ samples prepared by addition of Co/CNT during the zeolite synthesis contain a higher fraction of cobalt silicate or aluminates, which are not active for the reaction. Interestingly, when comparing the activity of the catalysts on the basis of reducible cobalt (Table 3), both $\mathrm{CoCNT}_{(10-20)} / \mathrm{ZSM}-5$ and $\mathrm{CoCNT}_{(20-40)} / \mathrm{ZSM}-5$ displayed a 5 to 10 times higher $\mathrm{FT}$ rate compared to the impregnated samples.

Figure 6. Molar distribution of liquid products by carbon number. Isomer represents the total amount of isomerized products in the gas fraction. a represents the chain growth coefficient for the ASF distribution.

The higher activity per reducible cobalt observed on the samples obtained by zeolite germination on Co/CNT can be linked to their enhanced mesoporous structure. Cobalt $\mathrm{CoCNT}_{(10-2)} / \mathrm{ZSM}-5$ and $\mathrm{CoCNT}_{(20-40)} / \mathrm{ZSM}-5$ display much higher mesoporous volume. During the catalyst preparation, cobalt metal nanoparticles introduced using the Co/CNT sacrificial templates are distributed more uniformly within the zeolite mesopores than in the catalysts prepared by impregnation. In addition, catalyst mesoporosity enhanced in CoCNT/ZSM-5 compared to other cobalt zeolite catalysts facilitates diffusion of the reagents and intermediates and removal of the reaction products. The cobalt 
metal nanoparticles size is also known to be an important factor for the FT synthesis performance [48]. The average size of cobalt oxide crystallites calculated from XRD in all samples was between 27 and $40 \mathrm{~nm}$. In contrast to the samples prepared by impregnation, the TEM images of $\mathrm{CoCNT}_{(10-20)} / \mathrm{ZSM}-5$ and $\mathrm{CoCNT}_{(20-40) / Z S M-5}$ (Figures 2 and 4 ) clearly show the presence of $\mathrm{Co}_{3} \mathrm{O}_{4}$ particles with the size between 1 and $5 \mathrm{~nm}$. Some of these nanoparticles are probably located in the zeolite micropores.

Table 3 also shows hydrocarbon selectivities observed in FT synthesis on cobalt-zeolite catalysts for $\mathrm{CO}$ conversions in the range of 28 and $42 \%$. Previous reports [3,13,16] suggest very small impact of variation of conversion between 30 and $40 \%$ on the reaction selectivity. The methane selectivity varies between 13 and $37 \%$. The samples synthesized by impregnation, i.e. Co/ZSM-5, $\mathrm{Co}_{(10-20)} / \mathrm{ZSM}-5$ and $\mathrm{Co}_{(20-40)} / \mathrm{ZSM}-5$, display much higher selectivity towards methane formation when compared to $\mathrm{CoCNT}_{(10-20)} / \mathrm{ZSM}-5$ and $\mathrm{CoCNT}_{(20-40)} / \mathrm{ZSM}-5$. Notably, methane selectivity was between 1.8 and 2.9 times lower when Co/CNT was present during zeolite synthesis. Similarly, the $\mathrm{C}_{2}-\mathrm{C}_{4}$ hydrocarbon selectivity was also higher in the samples obtained by cobalt impregnation, in particular on $\mathrm{Co}_{(20-40)} / \mathrm{ZSM}-5$. Metal particle sizes and their location in the zeolite can explain the selectivity towards short carbon-chain products and methane observed on the impregnated samples. Indeed, during the impregnation, cobalt can diffuse inside the zeolite framework generating small particles, in addition to the larger metal particles located on the zeolite external surface. The diffusion limitations and smaller metal particles inside the zeolite framework can result in higher methane and lower carbon-chain products selectivities [7]. Lower methane selectivity observed on the CoCNT/ZSM-5 samples could be also due to partial dissolution of extremely small cobalt nanoparticles during zeolite germination around these cobalt species. The occurrence of higher diffusion limitations in the impregnated samples is also consistent with the higher paraffin to olefin ratio (Table 3 ) observed for the impregnated samples. Higher paraffin yields are linked to the higher rate of olefin secondary hydrogenation, which are favored when diffusion limitations and olefin residence time in the zeolite pores are more significant.

The liquid product distribution is shown in Figure 6 , with the respective $n$-paraffin and isomer product selectivity. Independently of the synthesis procedure, none of the zeolite based catalysts yielded products with more than 25 carbon atoms. Thus, it is possible to assert that the zeolite support is responsible for the reduction of the carbon chain of the FT products. Note that cobalt catalyst on non-acidic supports at similar reaction conditions show formation of long-chain hydrocarbons with up to 50 carbon atoms [13]. This phenomenon is reflected by the chain growth probability $(\alpha)$ in the Anderson-Schulz-Flory distribution. Figure S3, SI clearly shows modification of the Anderson-Schulz-Flory plot for $\mathrm{CoCNT}_{(10-20)} / \mathrm{ZSM}-5$ which was synthetized using $\mathrm{Co} / \mathrm{CNT}$ as sacrificial templates compared to other catalysts. Under similar reaction conditions and on a non-acid support, e.g. $\mathrm{SiO}_{2}, \alpha$ is commonly around 0.85 for cobalt-based catalysts [13], whereas for the samples in this study the chain growth probability was between 0.58 and 0.68 .

The catalytic data suggest strong influence of the zeolite on both isomerization and cracking. On the one hand, the reaction products over cobalt zeolite composites contained significant amounts of isomers because of olefin isomerization on the zeolite Brønsted acid sites (Figure 5). On other hand, the carbon chain length over the cobalt zeolite catalysts was much shorter than on silica-supported counterparts. The reduction of the carbon chain growth when using zeolite supports for the FT synthesis is generally attributed to the occurrence of cracking reactions over Brønsted acid sites. The long-chain hydrocarbons resulting from the FT synthesis undergo cracking and isomerization on the zeolite acid sites leading to the formation of the shorter branched hydrocarbons. Indeed, the presence of isomerized hydrocarbons in the wax was observed for all catalysts. The proportion between isomerized products and linear paraffins was largely influenced by the catalyst synthesis procedures. Among the impregnated samples, the selectivity towards isomerization products was higher on Co/ZSM-5 followed by $\mathrm{Co}_{(10-20)} / Z S M-5$ and $\mathrm{Co}_{(20-40)} / Z S M-5$, respectively with isomer fractions of $57 \%, 48 \%$, and $35 \%$. Interestingly, CoCNT $_{(10-20)}, Z S M-5$ displayed the highest selectivity towards isomerization products, i.e. fraction of branched isomers of $63 \%$. It is important to mention that hydrocarbons with a higher isomerization degree are more likely to lead to the formation of tertiary carbocations, which however, can undergo $\beta$-scission [49]. Moreover, because of longer residence time in the zeolite micropores, the long chain hydrocarbons are more likely to undergo cracking [50]. Therefore, lower isomerization selectivity observed on the impregnated samples might be linked to a higher cracking rate of the long chain hydrocarbons. The higher selectivity to the $\mathrm{C}_{2}-\mathrm{C}_{4}$ hydrocarbons, and consequent lower $\mathrm{C}_{5+}$ hydrocarbon yield, observed for the impregnated samples could be due to the cracking of larger molecules.

The occurrence of primary and secondary cracking reactions in zeolite materials is often attributed to diffusion limitations [51]. Indeed, a longer residence time of the molecules in the vicinity of acid sites increases the probability of hydrocarbons to undergo cracking while shorter residence time of long chain hydrocarbons in proximity of zeolite acid sites would favor isomerization. The porosity of the impregnated sample is mostly constituted by micropores, while $\mathrm{CoCNT}_{(10-20)} / \mathrm{ZSM}-5$ and $\mathrm{CoCNT}_{(20-40)} / \mathrm{ZSM}-5$ have significant mesoporous volume created by the CNT sacrificial templates. The diffusion of higher hydrocarbons is therefore enhanced in the CoCNT/ZSM-5 catalysts which reduces their residence time inside the zeolite pores and probability of cracking. This suggestion is consistent with higher selectivity to longer carbon chain hydrocarbons observed on $\mathrm{CoCNT}_{(10-20)} / \mathrm{ZSM}-5$ and $\mathrm{CoCNT}_{(20-40)} / \mathrm{ZSM}-5$ (Table 3 ). Additionally, the higher cracking reaction rate on the impregnated samples would explain the lower isomerization selectivity on the impregnated catalysts, since the cracking rate of branched hydrocarbons is several orders of magnitude higher [52] than for linear conterparts. On $\operatorname{CoCNT}_{(10-20)} Z \mathrm{ZSM}-5$ and $\mathrm{CoCNT}_{(20-40)} / \mathrm{ZSM}-5$, the molecules produced by FT synthesis can diffuse more easily, due to higher mesoporous volume of 
the samples. Therefore, the cracking reactions rate lessened due to the faster diffusion and removal of the isomerized products. This improves isomerization selectivity and selectivity toward long chain hydrocarbons.

The synthesis of zeolite in the presence of cobalt impregnated CNT avoids the zeolite pore plugging during cobalt impregnation while generating a complementary mesoporous structure in the zeolite support. Consequently, the diffusion is improved enabling a reduction in the methane and $\mathrm{C}_{2}-\mathrm{C}_{4}$ hydrocarbon selectivities. Additionally, the liquid products are mainly composed of hydrocarbons up to $\mathrm{C}_{20}$ with a higher degree of isomerization. Therefore, the catalysts on the basis of mesoporous zeolites synthesized using carbon nanotubes with cobalt nanoparticles as sacrificial templates are more suitable for the direct production of fuels from syngas than conventional cobalt zeolite supported catalysts prepared by impregnation.

\section{Conclusion}

The use of cobalt impregnated CNT as sacrificial template enables direct synthesis of cobalt / ZSM-5 mesoporous composite catalysts. The synthesized catalyst had significantly higher mesoporous volume when the synthesis was performed in the presence of Co/CNT than pristine CNT. The morphology was also strongly affected by the zeolite synthesis method. The samples prepared during zeolite synthesis using the Co/CNT sacrificial templates showed clearly expressed layered structure. This indicates that the cobalt had an impact on the zeolite germination process. At the same time, the final samples had similar Si/Al ratio. The catalysts prepared by impregnated exhibited higher concentration of Lewis acid sites, while the catalysts prepared using Co/CNT showed higher amount of Brønsted acid sites. A significant amount of cobalt silicates was observed, when cobalt was present during the zeolite synthesis. The catalytic performance in FT synthesis was significantly affected by the catalyst synthesis procedure. The FT reaction rate normalized by reducible cobalt was $5-8$ time higher on the catalysts prepared using Co/CNT as sacrificial template. The higher mesoporous volume of the samples synthesized using Co/CNT during zeolite germination allows a faster diffusion of products and reagents, leading to longer chain products and a reduction of the cracking reactions while improving the selectivity to branched hydrocarbons.

The originality and major advantage of the developed method are relevant to simultaneous creation of zeolite mesoporous structure and introduction of cobalt nanoparticles within zeolite crystallites. Different to the techniques of post-synthesis introduction of cobalt, the method developed in this paper leads to a uniform distribution of cobalt nanoparticles within the zeolite mesoporous structure, enhanced diffusion and catalytic performance in FT reaction.

\section{Experimental Section}

Impregnation of carbon nanotubes with cobalt
Prior to the impregnation, the multi-walled carbon nanotubes (CNT) were treated with nitric acid to remove all metal contamination. Two different CNT samples (lolitec nanomaterial, 95\%) with different diameters, i.e. 10$20 \mathrm{~nm}$ and $20-40 \mathrm{~nm}$, were used. Typically, $3 \mathrm{~g}$ of CNT were pretreated in concentrated $\mathrm{HNO}_{3}(68 \%)$ in $210 \mathrm{~mL}$ during $14 \mathrm{~h}$ under reflux conditions. After, the samples were filtered, washed with distilled water until $\mathrm{pH}=7$ and dried at $100^{\circ} \mathrm{C}$ overnight.

Cobalt and platinum were introduced to CNT via wet impregnation method using respectively $\mathrm{Co}\left(\mathrm{NO}_{3}\right)_{2}{ }^{*} 6 \mathrm{H}_{2} \mathrm{O}$ (Sigma-Aldrich, 98\%) and $\mathrm{Pt}\left(\mathrm{NH}_{3}\right)_{4}\left(\mathrm{NO}_{3}\right)_{2}$ (Sigma-Aldrich) as precursors. Typically, $50 \mathrm{~mL}$ of $\mathrm{Co}\left(\mathrm{NO}_{3}\right)_{2}$ and $\mathrm{Pt}\left(\mathrm{NH}_{3}\right)_{4}\left(\mathrm{NO}_{3}\right)_{2}$ solution were used per gram of $\mathrm{CNT}$ and the precursor amount estimated to obtain a final composition of $20 \mathrm{wt} \%$ Co and $0.1 \mathrm{wt} . \% \mathrm{Pt}$. The mixture was submitted to ultrasonic treatment for 30 minutes and dried at $80^{\circ} \mathrm{C}$. The samples were calcined at $400{ }^{\circ} \mathrm{C}$ for $4 \mathrm{~h}$ under nitrogen atmosphere.

After the calcination, the samples were treated with $\mathrm{H}_{2} \mathrm{O}_{2}$ to restore the hydrophilic properties of the CNT. Typically, $30 \mathrm{~mL}$ of $1: 1 \mathrm{H}_{2} \mathrm{O}_{2}$ (SigmaAldrich, $35 \%$ ) and distilled water were added to $2.56 \mathrm{~g}$ of impregnated $\mathrm{CNT}$, sonicated for $30 \mathrm{~min}$ and dried at $80^{\circ} \mathrm{C}$.

\section{Synthesis of hierarchical cobalt - ZSM-5}

The ZSM-5 zeolite was synthesized by using the following initial composition of the gel: $2.7 \mathrm{NaCl}: 1 \mathrm{Al}_{2} \mathrm{O}_{3}: 12.5 \mathrm{TPAOH}: 55.8 \mathrm{SiO}_{2}: 7500 \mathrm{H}_{2} \mathrm{O}$. Sodium chloride ( $0.380 \mathrm{~g}$, Janssen Chimica, P.A.), tetrapropylammonium hydroxide ( $3.0 \mathrm{~g}$, Sigma-Aldrich, $1 \mathrm{M}$ in $\left.\mathrm{H}_{2} \mathrm{O}\right)$, sodium aluminate $(0.040 \mathrm{~g}$, Sigma-Aldrich) and distilled water were mixed until a clear solution was obtained. Then, Co/CNT $(0.3 \mathrm{~g})$ and tetraethyl-orthosilicate (TEOS, $2.8 \mathrm{~g}$, Sigma-Aldrich, $99 \%$ ) were added to the solution. After, the synthesis gel was aged for $1 \mathrm{~h}$ at room temperature under stirring. The synthesis gel was set inside a Teflon-lined autoclave $(40 \mathrm{~mL})$ and the zeolite crystallization performed under static condition at $170{ }^{\circ} \mathrm{C}$ for $24 \mathrm{~h}$. After cooling down, the solid was recovered by filtration and washed until neutral $\mathrm{pH}$. The final solid was calcined at $600{ }^{\circ} \mathrm{C}$ for $4 \mathrm{~h}$ under air. Thermogravimetric analysis showed complete decomposition and oxidation of cobalt-containing carbon nanotubes at temperatures below $400^{\circ} \mathrm{C}$. This suggests that cobalt zeolite composite catalysts calcined at $600^{\circ} \mathrm{C}$ in air did not contain any residual carbon species.

For comparison, zeolite syntheses without addition of CNT or in the presence of CNT, which did not contain cobalt ions, were performed. The prepared zeolites were impregnated with cobalt and platinum precursors in the final catalysts.

In order to obtain the zeolite acid form, two successive exchanges using $2 \mathrm{M} \mathrm{NH}_{4} \mathrm{NO}_{3}$ aqueous solution at $80^{\circ} \mathrm{C}$ for $1 \mathrm{~h}(1 \mathrm{~g}$ of zeolite per $50 \mathrm{~mL}$ of solution) were performed. The ammonium form was converted into the protonic form by calcination at $450{ }^{\circ} \mathrm{C}$ for $4 \mathrm{~h}$ under air.

\section{Catalyst characterization}

The samples were characterized by X-ray diffraction (XRD) by using a D8 advance diffractometer equipped with an energy dispersive type detector and a monochromatic $\mathrm{CuK}_{\alpha}$ radiation source. The samples were analyzed using a step of $0.02^{\circ}$ with an acquisition time of $0.5 \mathrm{~s}$. The average size of cobalt oxide $\left(\mathrm{Co}_{3} \mathrm{O}_{4}\right)$ crystallites was determined by the Scherrer equation. 
The sample chemical composition was determined by X-ray fluorescence (XRF) on a spectrometer M4 TORNADO (Bruker). This instrument is equipped with 2 anodes: rhodium X-ray tube $50 \mathrm{kV} / 600 \mathrm{~mA}(30 \mathrm{~W})$ and a tungsten X-Ray tube $50 \mathrm{kV} / 700 \mathrm{~mA}(35 \mathrm{~W})$. For sample characterization, the rhodium X-rays with a poly-capillary lens enabling excitation of an area of $200 \mu \mathrm{m}$ were used. The detector used was a Silicon-DriftDetector $\mathrm{Si}(\mathrm{Li})$ with $<145 \mathrm{eV}$ resolution at $100000 \mathrm{cps}\left(\mathrm{Mn} \mathrm{K}_{\alpha}\right)$ and cooled with a Peltier cooling $\left(253^{\circ} \mathrm{K}\right)$. The measurement was done under vacuum (20 mbar). Quantitative analysis was performed using fundamental parameter (FP) (standardless)

The textural properties of the samples were determined by $\mathrm{N}_{2}$ physisorption on a Micromeritics ASAP 2000 apparatus. Prior to analysis, the samples were degassed under vacuum $(10 \mu \mathrm{mHg})$ at $350{ }^{\circ} \mathrm{C}$ for $4 \mathrm{~h}$. The total pore volume (TPV) was calculated from the amount of vapor adsorbed at a relative pressure $P / P_{0}=0.97$. The samples surface area was estimated by the BET method, while the micropore volume and external surface were calculated using the deBoer t-plot method.

The catalyst reducibility was studied using temperature-programmed reduction (TPR) system with an Autochem II (Micrometrics) apparatus. The samples were reduced under a flow of $5 \% \mathrm{H}_{2}$ in $\operatorname{argon}(50 \mathrm{~mL} / \mathrm{min})$ and heated up to $800{ }^{\circ} \mathrm{C}$ at a rate of $5^{\circ} \mathrm{C} / \mathrm{min}$.

Comparative characterization of the acidic $\mathrm{OH}$ groups (Brønsted acid sites) and Lewis acid sites in solid acids, e.g. zeolites, was carried out using transmittance FTIR measurements in the $6000-900 \mathrm{~cm}^{-1}$ spectral range utilizing pyridine adsorption for monitoring the strength and relative quantities of both Lewis and Brønsted acid sites. FTIR transmittance measurements were performed at $\sim 30^{\circ} \mathrm{C}$ using self-supported disks of studied materials activated at $450^{\circ} \mathrm{C}$ for $5 \mathrm{~h}$ in vacuum (with the temperature ramp of $1^{\circ} \mathrm{C} / \mathrm{min}$ ). FTIR spectra have been collected using a Thermo iS10 spectrometer at a $4 \mathrm{~cm}^{-1}$ resolution $\left(0.96 \mathrm{~cm}^{-1}\right.$ data spacing) The spectra were analyzed and presented (including integration, differentiation and determination of peak positions) using specialized Thermo software, Omnic. Acidic properties of the samples were evaluated using temperature programmed desorption of pyridine (Py) monitored spectroscopically. An excess of Py was admitted into the transmittance cell at $150^{\circ} \mathrm{C}$, in a stepwise manner until no changes were observed in the spectra. The saturated sample was then evacuated for $10 \mathrm{~min}$ at $150^{\circ} \mathrm{C}$ to remove physically adsorbed $\mathrm{Py}$ and the FTIR spectrum collected. In the transmittance TPD experiments, Py was removed under vacuum in a stepwise fashion at $150-450^{\circ} \mathrm{C}$, and the FTIR spectra were obtained at each temperature step, every $50^{\circ} \mathrm{C}$. The intensity of the $\mathrm{Py}-\mathrm{L}$ and $\mathrm{Py}-\mathrm{H}+$ peaks at $\sim 1455$ and $1545 \mathrm{~cm}^{-1}$ was measured as a function of temperature, and the resulting plots used to compare the effective acidity of the samples.

The TEM observations of the samples were obtained by using a Tecnai instrument equipped with a LaB6 crystal operated at $200 \mathrm{kV}$. Before the analysis, the samples were dispersed by ultrasound in ethanol for $5 \mathrm{~min}$, and a drop of the suspension was deposited onto a carbon membrane on a 300 mesh copper grid. The STEM-HAADF tomographic analysis was carried out on a Jeol $2100 \mathrm{~F}$ (field emission gun) microscope operating at $200 \mathrm{kV}$ by using a spot size of $1.1 \AA$ with a current density of $0.5 p A^{*} \AA^{-1}$.

Catalytic tests

The catalytic performance of the samples was tested in FT synthesis. The experiments were performed in a milli-fixed bed reactor. All the details of the catalytic test relevant to mass and heat transfers are given in our earlier publication [53]. No significant ( $>0.5$ bar) pressure drop and temperature gradient are observed under the reaction conditions. Prior to testing, the samples were reduced in-situ in pure $\mathrm{H}_{2}$ gas flow $(3 \mathrm{~mL} / \mathrm{min})$ at $400^{\circ} \mathrm{C}$ for $4 \mathrm{~h}$ with a heating rate of $3^{\circ} \mathrm{C} / \mathrm{min}$. Then, the reactor was cooled down to room temperature, the flow switched to syngas $\left(\mathrm{H}_{2} / \mathrm{CO}=\right.$ 2 ) and the pressure adjusted to 20 bar. Nitrogen ( $5 \%$ of the $\mathrm{CO}$ flow) was used as internal standard. The flow was adjusted to obtain a GHSV of 20-70 L/g $\mathrm{g}_{\mathrm{Co}} . \mathrm{h}$. After achieving the desired pressure, the temperature was progressively increased to the reaction temperature, i.e. $250^{\circ} \mathrm{C}$, at a rate of $3^{\circ} \mathrm{C} / \mathrm{min}$. The reaction was conducted at $250^{\circ} \mathrm{C}$ in order to create in addition to FT synthesis favorable conditions for secondary reactions such olefin cracking and isomerization. The gas hourly space velocity (GHSV) was expressed in $\mathrm{cm}^{3} \mathrm{~g}_{\mathrm{cat}}{ }^{-1} \mathrm{~h}^{-1}$. The units correspond to the volume of syngas, which passed through $1 \mathrm{~g}$ of catalyst per hour. The gaseous reaction products, i.e. up to the $\mathrm{C}_{5}$ hydrocarbons were analyzed online using gas-chromatography (GC×FID/TCD, Varian, CP-3800). The liquid products were condensed under pressure and analyzed ex-situ using a Schimatzu 2010-Plus-AF gas-chromatograph.

\section{Acknowledgements}

The authors thank Dr Maya Marinova for the assistance with TEM measurements. They are very grateful to Prof. Ovidiu Ersen for his expertise in STEM-HAADF 3 D tomography. The supports of the Coordenação de Aperfeiçoamento de Pessoal de Nível Superior (CAPES) and French National Research Agency (ANR, DirectSynBioFuel and NANO4FuT projects) are kindly acknowledged.

Keywords: Hierarchical zeolites $•$ Cobalt $•$ Fischer-Tropsch synthesis $\cdot$ ZSM-5 $\bullet$, Carbon nanotubes $•$ Sacrificial templates

[1] A.Y. Khodakov, W. Chu, P. Fongarland, Chem. Rev. 2007, 107, 16921744.

[2] B.H. Davis, M.L. Occelli, Stud. Surf. Sci. Catal. 2006, 163, 1-420.

[3] Q. Zhang, K. Cheng, J. Kang, W. Deng, Y. Wang, ChemSusChem, 2014, 7, 1251-1264.

[4] H. Schulz, Catal. Today 2014, 228, 113-122

[5] G. Henrici - Olivé, S. Olivé, Angew. Chemie Int. Ed. 1976, 15, 136-141.

[6] C. Bouchy, G. Hastoy, E. Guillon, J.A. Martens, Oil Gas Sci. Technol. Rev. IFP 2009, 64, 91-112.

[7] V. Subramanian, K. Cheng, C. Lancelot, S. Heyte, S. Paul, S. Moldovan, O. Ersen, M. Marinova, V. V. Ordomsky, and A. Y. Khodakov, ACS Catal. 2016, 6, 1785-1792.

[8] V. V. Ordomsky, A. Y. Khodakov, B. Legras and C. Lancelot, Catal. Sci. Technol., 2014, 4, 2896-2899

[9] F. Pinto, R.N. André, C. Carolino, M. Miranda, Fuel Process. Technol. 2014, 126, 19-29.

[10] T.-S. Zhao, J. Chang, Y. Yoneyama, N. Tsubaki, Ind. Eng. Chem. Res. 2005, 44, 769-775.

[11] F.G. Botes, W. Böhringer, Appl. Catal. A. 2004, 267, 217-225.

[12] N. Tsubaki, Y. Yoneyama, K. Michiki, K. Fujimoto, Catal. Commun. 2003, 4, 108-111.

[13] V. Subramanian, V.L. Zholobenko, K. Cheng, C. Lancelot, S. Heyte, J. Thuriot, S. Paul, V. V. Ordomsky, A.Y. Khodakov, ChemCatChem 2016, $8,380-389$

[14] Z.W. Liu, X. Li, K. Asami, K. Fujimoto, Catal. Commun. 2005, 6, 503506.

[15] S. Bessell, Appl. Catal. A. 1995, 126, 235-244. 
[16] A. Carvalho, M. Marinova, N. Batalha, N. R. Marcilio, A. Y. Khodakov, and V. V. Ordomsky, Catal. Sci. Technol., 2017, 7, 5019-5027.

[17] D.J. Koh, J.S. Chung, Y.G. Kim, Ind. Eng. Chem. Res. 1995, 34, 19691975.

[18] K. Jothimurugesan, S.K. Gangwal, Ind. Eng. Chem. Res. 1998, 37, 1181-1188.

[19] G. Yang, C. Xing, W. Hirohama, Y. Jin, C. Zeng, Y. Suehiro, T. Wang, Y. Yoneyama, N. Tsubaki, Catal. Today 2013, 215, 29-35.

[20] X. Li, J. He, M. Meng, Y. Yoneyama, N. Tsubaki, J. Catal. 2009, 265, 26-34

[21] A. Martínez, J. Rollán, M.A. Arribas, H.S. Cerqueira, A.F. Costa, E.F. S.-Aguiar, J. Catal. 2007, 249, 162-173.

[22] A. Martínez, S. Valencia, R. Murciano, H.S. Cerqueira, A.F. Costa, E.F. Eduardo, Appl. Catal. A 2008, 346, 117-125

[23] Z.W. Liu, X. Li, K. Asami, K. Fujimoto, Fuel Process. Technol. 2007, 88, 165-170.

[24] S. Bessell, Appl. Catal. A 1993, 96, 253-268.

[25] K. Cheng, L. Zhang, J. Kang, X. Peng, Q. Zhang, Y. Wang, Chem. - A Eur. J. 2015, 21, 1928-1937.

[26] S. Sartipi, M. Alberts, M.J. Meijerink, T.C. Keller, J. Pérez-Ramírez, J. Gascon, F. Kapteijn, ChemSusChem 2013, 6, 1646-1650.

[27] M. Kustova, K. Egeblad, C.H. Christensen, A.L. Kustov, C.H Christensen, Stud. Surf. Sci. Catal. 2007, ???, 267-275.

[28] D.P. Serrano, J.M. Escola, P. Pizarro, Chem. Soc. Rev. 2013, 42 4004-4035.

[29] Y. Wang, Y. Jiang, J. Huang, J. Liang, H. Wang, Z. Li, J. Wu, M. Li, Y Zhao, J. Niu, Fuel 2016, 174, 17-24

[30] S. Sartipi, K. Parashar, M.J. Valero-Romero, V.P. Santos, B. Van Der Linden, M. Makkee, F. Kapteijn, J. Gascon, J. Catal. 2013, 305, 179190.

[31] J. Plana-Pallejà, S. Abelló, C. Berrueco, D. Montané, Appl. Catal. A 2016, 515, 126-135.

[32] Q. Lin, G. Yang, Q. Chen, R. Fan, Y. Yoneyama, H. Wan, N. Tsubaki, ChemCatChem 2015, 7, 682-689.

[33] G. Huang, P. Ji, H. Xu, J.-G. Jiang, L. Chen, P. Wu, Microporous Mesoporous Mater. 2017, 248, 30-39.

[34] D. Verboekend, J. Perez-Ramirez, Catal. Sci. Technol. 2011, 1, 879890.
[35] S. Yang, C. Yu, L. Yu, S. Miao, M. Zou, C. Jin, D. Zhang, L. Xu, S. Huang, Angew. Chemie Int. Ed. 2017, 56, 12553-12556

[36] P. Sazama, Z. Sobalik, J. Dedecek, I. Jakubec, V. Parvulescu, Z. Bast, J. Rathousky, H. Jirglova, Angew. Chemie Int. Ed. 2013, 52, 20382041

[37] Y. Fang, H. Hu, G. Chen, Microporous Mesoporous Mater 2008, 113, 481-489.

[38] L. Tosheva, V. Valtchev, J. Sterte, Micropor. Mesoporous Mater. 2000 $35,621-629$.

[39] F.-S. Xiao, L. Wang, C. Yin, K. Lin, Y. Di, J. Li, R. Xu, D.S. Su, R. Schlögl, T. Yokoi, T. Tatsumi, Angew. Chemie Int. Ed. 2006, 45, 3090 3093

[40] C. Huang, Z. Ma, P. Xie, Y. Yue, W. Hua, Z. Gao, J. Mol. Catal. A 2015 400, 90-94.

[41] E. Van Steen, G.S. Sewell, R.A. Makhothe, C. Micklethwaite, H. Manstein, M. De Lange, C.T.O. Connor, J.Catal. 1996, 229, 220-229.

[42] S.J. Jong, S. Cheng, Appl. Catal. A 1995, 126, 51-66.

[43] Y. Yao, F. Cao, J. Gu, Y. Wu, Y. Zhou, J. Wang, J. Porous Mater. 2013, 20, 891-896.

[44] S.N. Azizi, S. Ehsani Tilami, J. Solid State Chem. 2013, 198, 138-142.

[45] Q. Wang, J. Wang, Y. Zhou, X. Lin, J. Porous Mater. 2013, 20, 15191523.

[46] A. Rokicińska, M. Drozdek, B. Dudek, B. Gil, P. Michorczyk, D. Brouri, S. Dzwigaj, P. Kuśtrowski, Appl. Catal. B 2017,.212, 59-67.

[47] G.A.. Mekhemer, H.M.. Abd-Allah, S.A.. Mansour, Colloids Surfaces A Physicochem. Eng. Asp. 1999, 160, 251-259.

[48] Oyvind Borg, P.D.C. Dietzel, A.I. Spjelkavik, E.Z. Tveten, J.C Walmsley, S. Diplas, S. Eri, A. Holmen, E. Rytter, J. Catal. 2008, 259, $161-164$.

[49] J.A. Martens, M. Tielen, P.A. Jacobs, Catal. Today 1987, 1, 435-453.

[50] A. Corma, P.J. Miguel, A. V. Orchillés, Appl. Catal. A 1994, 117, 29-40.

[51] S. van Donk, A.H. Janssen, J.H. Bitter, K.P. de Jong, Catal. Rev. 2003 45, 297-319.

[52] J. Weitkamp, S. Ernst, Catal. Today 1994, 19, 107-149.

[53] S. Chambrey, P. Fongarland, H. Karaca, S. Piché, A. Griboval-Constant D. Schweich, F. Luck, S. Savin, A.Y. Khodakov, Catal. Today 2011, 171, 201-206. 


\section{Entry for the Table of Contents}

Layout 1:

\section{FULL PAPER}

Major increase in mesoporous volume and iso-paraffin synthesis rate from syngas over cobalt zeolite nanocomposites prepared using cobalt carbon nanotube sacrificial templates

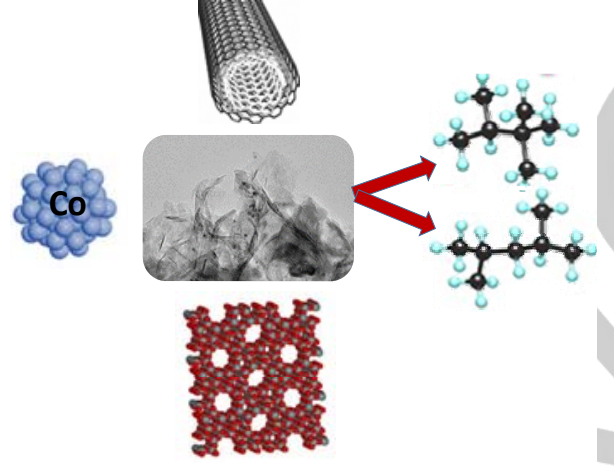

Camila Flores, Nuno Batalha, Vitaly V. Ordomsky, Vladimir L.

Zholobenko, Walid Baaziz, Nilson R. Marcilio and Andrei Y. Khodakov*

Page No. - Page No.

Direct Production of Iso-Paraffins from Syngas over Hierarchical Cobalt-ZSM-5 Nanocomposites Synthetized using Carbon Nanotubes as Sacrificial Templates 